\title{
Obesity and hepatotoxins as risk factors for fatty liver disease
}

\author{
M Hodgson, D H van Thiel, B Goodman-Klein
}

\begin{abstract}
Generally fatty liver disease (FLD) is attributed either to alcohol, diabetes mellitus, or obesity. To evaluate this commonly held clinical belief, a case-control study of FLD in Western Pennsylvania was conducted with 19 cases being identified over a two year period. Cases of FLD were significantly heavier and were significantly more likely than controls to have exposures to either agents with recognised animal hepatotoxicity (odds ratio[OR] $\infty$, $p=0.018$ ) or to agents with potential hepatotoxicity-that is, documented in humans, animals, or expected on the basis of structure activity relations $(O R=4.5 ; p=0.018)$. By contrast, they had not consumed significantly more alcohol than the controls. A logistic regression model of this experience suggests that both exposure to hepatotoxins and obesity are independent risk factors for FLD, which have an additive rather than a multiplicative interaction. Based upon these data, an occupational exposure to either recognised or potential hepatotoxins should be considered as a cause of liver dysfunction in subjects with FLD, independent of obesity and a history of alcohol consumption.
\end{abstract}

Liver disease and cirrhosis are the tenth leading causes of death and ninth leading causes of years of potential life lost before the age of $65 .^{1}$ Most cases of advanced liver disease are attributed to a hepatitis virus infection or alcohol abuse on the basis of either serological testing procedures or a history of alcohol abuse. ${ }^{2}$ Occupational exposure as a cause of liver disease is recognised only occasionally when massed outbreaks of liver disease occur. ${ }^{3}$ Occupational exposure is not recognised as an important risk factor

Departments of Medicine (Occupational and Environmental Medicine Program) and Surgery, University of Pittsburgh School of Medicine, Pittsburgh PA 15261, USA

M Hodgson, D H van Thiel, B Goodman-Klein in the pathoaetiology of sporadic cases of fatty liver disease (FLD). This lack of association is surprising as the liver is an organ that is crucial for the detoxification and excretion of many xenobiotics and might reasonably be expected to show at least intermittent signs of injury when an employee has been exposed to a potentially hepatotoxic agent at either an acute large dose or, even more likely, if the exposure has been chronic. Short exposures to such agents may lead to reversible FLD changes such as those that occur with a single large dose of alcohol. ${ }^{4}$ One model suggests that chronic low level exposures, as repeated insults, may in fact lead to greater long term damage than a single acute massive exposure.

The liver is known to have a surprisingly unique ability to regenerate, a process that actually contributes to cirrhosis particularly when the hepatic regeneration is intermittent and chronic. In clinical practice, liver injury tests as a group have a positive predictive value for the detection of chronic liver disease only in the range of 50 to $60 \% .^{6}$ Worse yet, minor abnormalities in liver injury tests are commonly disregarded either because their long term implications are uncertain or no specific therapy for a detected liver disease other than viral hepatitis currently exists in most cases.

Traditional approaches used to identify the aetiology of disease are based on the characterisation of risk factors that are identified in case-control studies. This approach has been eminently successful in identifying single causes of many chronic diseases and the interaction between various risk factors in disease characterised as having more than one risk factor. No such study has ever been undertaken for FLD. None the less, clinically recognised risk factors for FLD include diabetes mellitus, obesity, alcohol consumption, ${ }^{789}$ and possible exposure to other "hepatotoxins," 10 although the last has only been identified rarely and then only in epidemic situations.

Recently, an occupational exposure to a potential hepatotoxin has been identified as a cause of sporadic FLD in several persons in whom the FLD could not be explained as occurring as a result of either alcohol abuse or the presence of diabetes mellitus. Based upon this preliminary experience, a case-control 
study of incident cases of FLD was instituted through the cooperation of seven participating gastroenterology (GI) groups in the greater Pittsburgh area. The primary hypothesis was that FLD results from exposure to agents with recognised hepatotoxicity and such hepatic injury can occur independently of the presence of coexisting obesity.

\section{Materials and methods}

Cases were identified by contacting seven participating GI groups in the Pittsburgh area on a regular basis. All identified cases were recruited actively to avoid ascertainment bias. The initial four cases of FLD identified through a consultation service was also included. Criteria for entry included the presence of a liver biopsy showing fatty liver disease and an age between 18 and 65 . Alcoholic abuse, as a cause for the FLD, was excluded by including patients for study only if they reported consuming less than 4 ounces $(113 \mathrm{~g})$ of alcohol a day at the time of diagnosis and this report was in agreement with the impression of the treating primary care physician. Viral hepatitis as a cause for the FLD was excluded by restricting patients to those without a history of previous blood transfusions, intravenous drug use, or homosexual or bisexual lifestyle and those without any serological evidence of either current or previous hepatitis B. The study was conducted before serological testing for hepatitis $\mathrm{C}$ virus became commercially available. Fatty liver disease was defined as the finding of $5 \%$ or more of the liver biopsy showing fatty change and the absence of any regenerative nodules. The characteristics of the cellular infiltrate and the presence or absence of perivenular and perisinusoidal fibrosis were not used as exclusion criteria. Finally, patients who were identified through the occupational and environmental medicine clinic or those who were referred for an evaluation of a potential occupational cause of their liver disease were excluded to avoid any case ascertainment selection bias.

Controls were also obtained through three participating GI practices as similar sociodemographic characteristics were to be expected in the two groups. They were matched for sex and age within five years of the cases. All patients with recognised pre-existing disease unrelated to the liver were eligible, including those with diseases at least potentially related to solvent exposures although none were present in the study. Subjects were excluded as controls if they had been told that they had ever had any liver disease in the past. No attempt was made to exclude controls if they had consumed more than 4 ounces of alcohol a day in the past.

The medical record of each case was reviewed and an occupational history was obtained by one of us (MH). When subjects were unsure of their exposures to recognised or suspected hepatotoxic agents, material safety data sheets (MSDS) were requested from their employers. The potential role of alcohol consumption in the pathogenesis of FLD was explored by characterising the alcohol consumption of the cases at three separate points in time: maximal use, currently, and at the time of any potential exposure to hepatotoxin. A range of consumption of beer, wine, and spirits at a sitting and a frequency of sittings were then obtained for each period, and an average quantity of alcohol use was determined. A final number for maximum, usual, and current alcohol consumption data was identified and coded to a quantity of alcohol in ounces a week by multiplying beer by $5 \%$, wine by $11 \%$ and spirits by $40 \%$. All laboratory studies in medical charts were reviewed for the presence of any evidence of liver injury in the controls. No effort was made to identify cases for the presence of microvesicular fat, ${ }^{10}$ as all histopathology specimens were prepared with defatting alcohol concentrations that would eliminate such a possibility.

All exposures were first coded by $\mathrm{MH}$ to one of four categories and then by duration, intensity, frequency, and latency according to methods developed and reported elsewhere. ${ }^{112}$ Agents were classified as known human hepatotoxins if liver disease had been attributed to such exposure convincingly in humans both in epidemiological studies and through recognised pathophysiological mechanisms. Agents were classified as animal hepatotoxins if they had been shown to have hepatotoxicity in at least two different strains of animals. The presence of case reports implicating hepatotoxicity in humans was not considered adequate evidence for hepatotoxicity. Agents were classified as potential hepatotoxins if they could be predicted on the basis of their structure to have hepatotoxic activity but had either never been studied or had not been convincingly documented as actually being a hepatotoxin. Finally, agents were classified as "other solvents" if they could not be further identified or had never been associated with hepatotoxicity; this classification was not used, however, as no solvents were coded to this class. For example, perchloroethylene, an agent well recognised to cause disease in humans, was considered to be a clear human hepatotoxin. Agents that have been associated with animal hepatotoxicity and anecdotally with human hepatotoxicity, such as $1,1,1$, trichloroethane and dichloromethane, were coded as animal hepatotoxins. Agents that could be predicted to have hepatotoxicity on the basis of algorithms but for which studies either have not been conducted or one or two studies have failed to show hepatotoxicity were classified as potential hepatotoxins. One of us (BGK) independently reviewed all the charts blinded to case-control state to review the coding for fulfilment of those criteria and to validate the exposure intensity variables recorded by $\mathrm{MH}$. 
Data were double entered into a microcomputer and analysed with standard statistical software packages including DataEase, SPSSPC 2.0, and Egret. Standard statistical tests were used, including McNemar's, Wilcoxon, and paired and unpaired $t$ tests. Where a specific hypothesis had been formulated, one sided tests were used with an $\alpha$ level of 0.05 considered to be significant. For completeness, two sided $95 \%$ confidence intervals $(95 \% \mathrm{CI})$ are provided. Where comparisons were undertaken that had not been formulated as part of an initial study hypothesis, two sided probabilities were used. Initial power calculations for the case-control study had suggested that 80 cases were needed to provide $\alpha=0.05$ and $B=0.2$ under our original assumptions.

Three risk factors were defined. The first was morbid obesity, which was defined as a body mass index (BMI; weight $\left.(\mathrm{kg}) /(\text { height }(\mathrm{m}))^{2}\right)$ greater than 30. The second was a maximal usual daily alcohol consumption over several months at some point in the past greater than 4 ounces a day. After review of the data few subjects had consumed quantities approaching this amount, and a second analysis was undertaken using a cut off quantity of one ounce a week. Finally, exposure to any hepatotoxins, either recognised or potential human or animal, was considered to be of interest. All statistical comparisons of matched groups were performed using paired (conditional) testing. A model was developed using logistic regression. Independent variables were selected if they were significantly different between cases and controls in preliminary univariate analyses.

The study was terminated prematurely because of concern over the introduction of selection bias into later cases. Specifically, we had been asked by the participating GI physicians to evaluate two patients (cases 20 and 21) and told that a biopsy would be done if an exposure history was positive. If no evidence of exposure was obtained by us, the referring physicians planned to observe the patients over a longer period.
As several further patients were then unambiguously referred specifically for the evaluation of occupational exposures from these same referring GI groups, putative exposure to toxin may have become a factor contributing to the identification of cases and the investigators were concerned that subjects without a potential exposure history may not have been considered either for biopsy or referral. ${ }^{13}$ Exclusion of these cases-that is, those without exposure-would then have inflated the odds ratios (ORs) inappropriately by including more cases with exposure and excluding cases without such exposures. Interestingly, either the rate of liver biopsies or the number of new cases of FLD among participating groups appeared to have decreased in the first year of the study, as we had originally expected 30 to 40 new cases a year based upon the rate of occurrence of such cases as part of an earlier pilot study.

As a result, the present study was terminated, and we have pursued our orginal hypothesis using a completely different referral source and patient selection criteria that should avoid this particular bias. As the patients in the new study do not meet the same entry criteria, these subjects have been excluded from this report and are expected to be the basis of a separate publication.

\section{Results}

Nineteen consecutive cases of FLD were identified over a two year period. Table 1 presents the demographic and exposure variables obtained on these 19 patients and the controls. Patients with liver disease were significantly more obese than were the controls (paired $t=2 \cdot 25, \mathrm{p}=0.019$ ). At the time of their examination, after a histological diagnosis of FLD was made, they consumed less alcohol as a group than did the controls. Using non-parametric statistics and appropriate (log) transformations, no significant differences were seen between the cases and the controls in the reported maximum amount of

Table 1 Demographic and exposure characteristics of cases and controls by sex

\begin{tabular}{|c|c|c|c|c|}
\hline & \multicolumn{2}{|l|}{ Cases } & \multicolumn{2}{|l|}{ Controls } \\
\hline & $\operatorname{Men}(\operatorname{mean}(S D))$ & Women (mean (SD)) & $\operatorname{Men}(\operatorname{mean}(S D))$ & Women (mean $(S D)$ ) \\
\hline $\begin{array}{l}\text { Mean age (y) } \\
\text { Mean BMI } \\
\text { History of diabetes } \\
\text { Maximum alcohol consumption } \\
\quad \text { (ounces/week) }\end{array}$ & $\begin{array}{l}36 \cdot 8(4 \cdot 0) \\
29 \cdot 6(3 \cdot 1) \\
1(10) \\
22 \cdot 0(58 \cdot 8)\end{array}$ & $\begin{array}{l}46 \cdot 2(4 \cdot 3) \\
33 \cdot 9(3 \cdot 3) \\
0 \\
0 \cdot 8(1 \cdot 6)\end{array}$ & $\begin{array}{l}38 \cdot 5(4 \cdot 1) \\
27 \cdot 0(5 \cdot 1) \\
0 \\
6 \cdot 6(6 \cdot 3)\end{array}$ & $\begin{array}{l}44 \cdot 7(3 \cdot 9) \\
26 \cdot 6(4 \cdot 3) \\
1(11) \\
1 \cdot 0(2 \cdot 4)\end{array}$ \\
\hline $\begin{array}{l}\text { \% with exposure to: } \\
\text { Animal hepatotoxins } \\
\text { Human hepatotoxins } \\
\text { Potential hepatotoxins }\end{array}$ & $\begin{array}{l}5(50) \\
3(20) \\
2(20)\end{array}$ & $\begin{array}{l}2(22) \\
0 \\
3(33)\end{array}$ & $\begin{array}{l}0 \\
0 \\
2(20)\end{array}$ & $\begin{array}{l}0 \\
1(11) \\
1(11)\end{array}$ \\
\hline $\begin{array}{l}\text { Mean duration of exposure to: } \\
\text { Animal hepatotoxins } \\
\text { Human hepatotoxins } \\
\text { Potential hepatotoxins }\end{array}$ & $\begin{array}{l}0.4(0.52) \\
0.3(0.5) \\
0.9(1.9)\end{array}$ & $\begin{array}{l}0 \cdot 2(0 \cdot 4) \\
0(0) \\
1 \cdot 7(3 \cdot 6)\end{array}$ & $\begin{array}{l}0 \\
0(0) \\
0 \cdot 7(2 \cdot 0)\end{array}$ & $\begin{array}{l}0 \\
0 \cdot 1(0 \cdot 3) \\
0 \cdot 75(2 \cdot 2)\end{array}$ \\
\hline
\end{tabular}


alcohol ever, or usually consumed, or both. The numerically higher value for the FLD cases was due to one heavy alcohol user who had consumed a calculated average of 189 ounces of alcohol a week. No differences existed between cases and controls for a history of diabetes mellitus (one case and one control), the casual use of paint strippers, pesticides, glues for model building or sniffing, and spot removers.

Cases had a more frequent history of exposure to human hepatotoxins (OR $=3, p=0.31)$, to animal hepatotoxins $(\mathrm{OR}=\infty, 95 \% \mathrm{CI}$ not calculable, $\mathrm{p}=0.016)$, and to agents with potential hepatotoxicity $(O R=2, p=0.341)$. Cases were 4.5 times more likely than controls to be exposed to any one of the three $(\mathrm{OR}=4.5,95 \%$ CI 0.87-34.59, $p=0.035$ ). Moreover the duration of exposure to agents of interest was longer among the cases but was not statistically significant except for a history of exposure to animal hepatotoxin. Cases with exposures to human, animal, or potential hepatotoxins did not differ in age or BMI as a group from cases without such exposures. On the other hand, cases with exposures to animal hepatotoxins consumed less alcohol at the time of their maximum consumption (Mann-Whitney $\mathrm{U}$ test: $\mathrm{Z}=-\mathbf{1} \cdot 8$, $p=0.067)$. Cases with exposures to human or potential hepatotoxins consumed less alcohol on average at the time of their maximum usual ingestion than did cases without such exposure but not to a degree approaching statistical significance. In general, female cases had a lower BMI and consumed less alcohol than did male cases.

Cases were significantly more likely to have more risk factors than the controls. At least one risk factor was found in $15(79 \%)$ of cases but only in nine $(47 \%)$ of the controls. Nine cases and only one control had two risk factors. A Wilcoxon signed rank test suggested that the cases had significantly more risk factors $(Z=-1.68, p=0.041)$ than did controls. When regular alcohol consumption was redefined as at least 1 ounce of alcohol consumed a week and that level was used as the cut off defining a risk of alcohol, the results of a Wilcoxon test were consistent with this as a risk factor $(Z=2 \cdot 6, p=0.009)$.

Table 2 presents the clinical characteristics of interest for each of the cases with the exposures considered to be of possible interest. Exposures were classified as human, animal, or agents with predictable but undemonstrated toxicity as defined in the

Table 2 Clinical characteristics of cases with occupational exposures

\begin{tabular}{|c|c|c|c|c|c|c|}
\hline Age & Sex & Industry & Occupation & Exposures & $B M I$ & $\begin{array}{l}\text { Maximum } \\
\text { usual alcohol } \\
\text { consumption } \\
\text { (ounces/week) }\end{array}$ \\
\hline 57 & $\mathbf{M}$ & & $\begin{array}{l}\text { Housewife/paint } \\
\text { stripping }\end{array}$ & $\begin{array}{l}\text { Used methylene chloride based paint } \\
\text { strippers } 4-6 \text { hours/day, } 5 \text { days a } \\
\text { week for }>5 \text { years without } \\
\text { personal protective equipment } \dagger\end{array}$ & $24 \cdot 9$ & 4.9 \\
\hline 24 & $\mathbf{M}$ & Service & Beautician & $\begin{array}{l}\text { Uses spray cans (fixatives, } \\
\text { propellants) } \neq \text {, thioglycollates }\end{array}$ & 41.9 & 0.4 \\
\hline 40 & $\mathbf{M}$ & Printing & Printer & $\begin{array}{l}\text { Glycol ethers } \dagger \text {, aromatic/aliphatic } \\
\text { hydrocarbons } \ddagger \text {, vinyl acetate } \\
\text { copolymer }\end{array}$ & $45 \cdot 6$ & $0 \cdot 1$ \\
\hline 59 & $\mathbf{M}$ & Printing department & Secretary & $\begin{array}{l}\text { Sat next to a disposal sink for blanket } \\
\text { washer for } 11 \text { years; } \\
\text { trichloroethylene } \dagger \text {, glycol ethers } \dagger \text {, } \\
\text { inks }\end{array}$ & $36 \cdot 6$ & $0 \cdot 1$ \\
\hline 45 & $\mathbf{M}$ & Healthcare products & $\begin{array}{l}\text { Printing machine } \\
\text { operator }\end{array}$ & $\begin{array}{l}\text { Cleaned spray machine and self } \\
\text { several times per shift with acetate } \\
\text { for } 2 \text { years } \ddagger\end{array}$ & $29 \cdot 4$ & $0 \cdot 1$ \\
\hline 19 & W & & & $\begin{array}{l}\text { Ingestion of petroleum distillates } \\
\text { (furniture polish) } \ddagger \text { at the age of } 6 \\
\text { with treatment in hospital for } \\
\text { acute liver disease }\end{array}$ & $27 \cdot 1$ & 0.0 \\
\hline 25 & $\mathbf{W}$ & Powder & $\begin{array}{l}\text { Quality assurance } \\
\text { inspector }\end{array}$ & $\begin{array}{l}\text { Worked with } 1,1,1 \text { trichloroethane } \\
1-2 \text { hours a day in a cold bath. He } \\
\text { also worked with } \\
\text { perchloroethylene }{ }^{\star} \text { intermittently }\end{array}$ & $34 \cdot 2$ & $4 \cdot 8$ \\
\hline 28 & $\mathbf{W}$ & Basic steel & $\begin{array}{l}\text { Process control } \\
\text { technician }\end{array}$ & $\begin{array}{l}\text { Worked around } 1,1,1 \text { trichlorethane } \\
30 \text { minutes to } 8 \text { hours a day around } \\
\text { a hot bath. He also worked with } \\
\text { perchloroethylene }{ }^{\star} \text { intermittently }\end{array}$ & $29 \cdot 6$ & $3 \cdot 6$ \\
\hline 31 & $\mathbf{W}$ & Fibreglass & Operator & $\begin{array}{l}\text { Worked with a vinyl-butadiene } \\
\text { polymer } 30 \% \text { of the time with skin } \\
\text { and inhalation contact } \ddagger\end{array}$ & $27 \cdot 8$ & 0.3 \\
\hline 33 & $\mathbf{W}$ & Basic steel & Maintenance & $\begin{array}{l}\text { Spent one day spraying } 1,1,1 \\
\text { trichloroethane } \dagger\end{array}$ & $30 \cdot 6$ & $14 \cdot 4$ \\
\hline 43 & $\mathbf{W}$ & Coal & Lab technician & $\begin{array}{l}\text { Floated coal in perchloroethylene } \\
\text { and ethylene dibromide } \dagger\end{array}$ & $31 \cdot 0$ & 0.6 \\
\hline
\end{tabular}

^Known human hepatotoxins; †animal hepatotoxins; łpotential hepatotoxins.

$M=$ Man; $\mathbf{W}=$ woman. 
methods section. Morbid obesity (BMI $>30$ ) was present in six, with two more $(B M I>29)$ almost meeting these criteria, for a total of $73 \%$. An average regular alcohol consumption rate greater than 4 ounces a day at some time in the past was present in only one $(5.2 \%)$ case. Working in the printing industry appeared to be a risk factor, as three cases but none of the controls worked in a job associated with the printing industry. Industrial quality assurance technicians were similarly at high risk, two through the use of halogenated hydrocarbon degreasers and one through chemically similar "coal floating" agents.

A logistic regression model was developed to examine the relative influence of the two risk factors that were significantly different between cases and controls. Obesity and exposure to hepatotoxin were not mutually exclusive. None the less, they did not appear interrelated. An interaction term was developed for obesity and exposure to any hepatotoxin. Body mass index contributed significantly to the model (log likelihood ratio statistic $=4 \cdot 182, \mathrm{p}=0.041$ ), as did the variable exposure to any hepatotoxin (log likelihood ratio statistic $=4 \cdot 163, p=0.035$ ). The addition of the interaction term or a term for sex did not contribute significantly to the model.

\section{Discussion}

Previous clinical studies and reviews of FLD have considered that this disease entity occurs in most cases as a consequence of obesity, diabetes mellitus, or alcohol abuse. ${ }^{714}$ None of these studies either examined or even discussed the presence of exposure to hepatotoxic agents. Our study suggests that exposure to agents with potential hepatotoxicity may contribute to sporadic cases of FLD, even though the toxicity has not always been clearly documented in humans. It suggests that obesity may also play an important part in the development of sporadic FLD. Cases with FLD but without exposure to hepatotoxin had consumed more alcohol than the cases with hepatotoxin exposure, raising the question that low levels of alcohol consumption ${ }^{15}$ may also contribute to the development of FLD. Diabetes mellitus was not identified as a major risk factor for FLD in this series. ${ }^{16}$ This finding may be due to the small size of the current sample. Other explanations are plausible. As glucose intolerance often accompanies the metabolic derangement of FLD, clinically manifest diabetes in such cases may be a result rather than a cause of their liver disease or be associated with the same underlying pathophysiology that supports the development of FLD.

Several authors have suggested that FLD may result either from an interaction of both nonoccupational and occupational exposures ${ }^{17}$ as well as from multiple non-occupational risk factors. ${ }^{18}$
Studies attempting to address exposures on the basis of historical evidence are at a distinct disadvantage because of the difficulties experienced with defining the "dose." Non-occupational agents, such as ethanol, frequently induce microsomal enzymes and enhance the toxicity of agents such as acetaminophen. Many hepatotoxins are microsomal enzyme inducers ${ }^{19}$ and not only produce direct toxic injury but also can potentiate the toxicity of other toxins. This study suggests that the presence of two independent risk factors leads to more FLD than does the presence of only one, although the enhancement appears to be a simple additive effect rather than a multiplicative one. We cannot exclude the possibility that the failure to find an interaction between risk factors might not be due to the sample size or even to the selection of a statistically inappropriate model. ${ }^{20}$

The current study does generate two important methodological concerns. Firstly, the number of cases is small. In this regard, it is important to recall that the study was terminated prematurely to prevent the introduction of bias, as a case-control study can only be as valid as the selection of its cases. We considered that a reasonably unbiased small group of cases was preferable to an inflated group of biased cases. As liver biopsies do not appear to be performed as frequently as in the past, despite the existence of substantial supporting publications, and because the number of cases recognised to have abnormal liver injury tests appeared to be decreasing, fewer cases became available for inclusion with increasing duration of the study. Small numbers of cases are known to contribute to statistically unstable estimates and to have a greater likelihod of probability errors. None the less, as the study confirmed a previous hypothesis, as all examined ORs were greater than $1 \cdot 0$, and as the study provided a biologically plausible result, it rejects the null hypothesis it was designed to test and awaits replication.

Secondly, the initial estimates of exposures were not coded blindly. Although this point may play a part in estimating intensity, frequency, or duration of exposure, the lack of blinding should not have led to a categorical overestimation of exposure frequency on our part. The second coding of exposure was in fact performed blindly and agreed with the initial coding. If controls are healthy and have no previous reason to suspect or remember exposures, recall bias on the part of cases may lead to a bias. As controls were selected with a disease in the same organ system, and were told that the study was attempting to identify occupational risk factors for gastrointestinal disease, the study design utilised should not have led to recall bias. Finally, there was no difference in the percentage of subjects coded as having exposure to the "other solvents" group, as might have been expected if investigator bias influenced the coding. The 
exposures of cases were obviously greater than those of controls and clustering in specific jobs with known risks did occur. Because of these findings, we believe that an exposure misclassification did not occur and the results should be considered valid.

We also considered alternative coding schemes based on metabolic pathways, such as cytochrome P450 or alcohol metabolism, rather than the classification used. Given the controversy over the involvement of one or another metabolic pathways in dichloromethane toxicity and the differences between animal and human metabolism in general, we chose not to pursue this particular strategy. In any case, several clusters of occupations were recognised to be at some increased risk for FLD. For example, three subjects worked in the printing industries. Exposure to halogenated hydrocarbons in degreasing procedures was a frequent activity. Neither of these two exposures was present among controls.

In summary, this study suggests that occupational exposures should be considered as a possible cause of FLD as well as the generally recognised factors of obesity and use of alcohol. When positive liver injury tests are seen, physicians should obtain an occupational history and determine the presence or absence of exposure to animal or human hepatotoxins as well as consider the role of BMI and use of alcohol as relevant factors contributing to the FLD. If these are present, exposure modifications should be considered.

This study was supported by grant $\mathrm{KOIOH} 00071-$ $01(\mathrm{NIOSH})$.

\section{Requests for reprints to: $\operatorname{Dr} M$ J Hodgson, Occupational and Environmental Medicine Program, School of Medicine, University of Pitts- burgh, 149 Lothrop Hall, 190 Lothrop Street, Pitts- burgh, PA 15261, USA.}

We thank Lewis Kuller, MD, Dr P H and Vincent Arena, $\mathrm{PhD}$ for their initial help in designing the project, Barbara Hanusa, MS for help with the logistic modelling, Geoffrey Block, MD, Dr P H for his thoughtful review, and Maria Lukasiewicz for clerical support. We also acknowledge the willingness of the participating gastroenterologists Drs Robert Chamovitz, Michael F Ennis, Kenneth A Glick, Toby Graham, Lee Hershenson, Fahrad
Ismail-Beigi, Thomas J Kelly, H David Lipsitz, Melvin Mallitt, Darrell K Reed, Shirish N Shah, Fred J Thaler, Richard L Wechsler, and John $M$ Wood to cooperate in acquiring patients.

1 Anon. Changes in premature mortality-United States, 198384. $M M W R$ 1986;36:29-31.

2 Anon. Deaths from chronic liver disease-United States 1986. $M M W R$ 1989;38:792-9.

3 Harrison R. Medical surveillance for workplace hepatotoxins. In: Rempel D, ed. Occupational medicine state of the art reviews 1990;5:515-30.

4 Nemesánszky E, Lott J, Arato $M$. Changes in serum enzymes in moderate drinkers after and alcohol challenge. Clin Chem 1988;34:525-7.

5 Tamburro C. Chemical hepatitis pathogenesis, detection and management. In: Med Clin North Am 1979;63:545-66.

6 Hodgson MJ, Van Thiel DH, Goodman-Klein B. Evaluating the liver. In: Gochfeld M, Favata E, eds. Medical surveillance in hazardous waste workers. Occupational medicine state of the art reviews, Vol 4. 1989.

7 Schaffner F, Thaler H. Nonalcoholic fatty liver disease. In: Progress in Liver Disease, Vol VIII 1986.

8 Holzbach RT. Nonalcoholic fatty liver-Structural and clinical implications. Cleve Clin J Med 1988;55:136-44.

9 Hodgson MJ, Van Thiel DH, Lauschus K, Karpf $M$. Liver injury tests in hazardous waste workers: The Role of Obesity. J Occup Med 1989;31:238-42.

10 Redlich CA, West AB, Fleming L, True LD, Cullen MR, Riely CA. Clinical and pathological characteristics of hepatotoxicity associated with occupational exposure to dimethylformamide. Gastroenterology 1990;99:748-57.

11 Gerin $M$, Siematyicki J, Kemper H, Begin D. Obtaining occupational exposure histories in epidemiologic case-control studies. J Occup Med 1985;27:420-6.

12 Goldberg MS, Siematyicki J, Gerin M. Inter-rater agreement in assessing occupational exposure in a case-control study. $\mathrm{Br} \mathrm{J}$ Ind Med 1986;43:667-76.

13 Van Ness MM, Diehl AM. Is liver biopsy useful in the evaluation of patients with chronically elevated liver enzymes? Ann Intern Med 1989;111:473-8; letters in response 1990;112:311.

14 Diehl AM, Goodman Z, Ishak KG. Alcohol like liver disease in nonalcoholics-a clinical and histologic comparison with alcohol-induced liver injury. Gastroenterology 1988;95: 1056-62.

15 Friedman LS, Dienstag JL, Watkins E, et al. Evaluation of blood donors with elevated serum alanine aminotransferase levels. Ann Intern Med 1987;107:137-44.

16 Van Thiel DH. Diabetes mellitus and hepatobiliary disease. Current Concepts in Gastroenterology 1985;10:3-11.

17 Edling $C$. Interaction between drugs and solvents as a cause of fatty change in the liver. $\mathrm{Br} J$ Ind Med 1982;39:198-9.

18 Shergy WJ, Polisson RP, Caldwell DS, Rice JR, Pisetsky DS, Allen NB. Methotrexate-associated hepatoxicity: retrospective analysis of 210 patients with rheumatoid arthritis. $\mathrm{Am} \mathrm{J}$ Med 1988;85:771-4.

19 Colombi A. Experience of testing microsomal enzyme induction in occupational and environmental medicine. In: Foa V, Emmett EA, Maroni M, Colombi A, eds. Occupational and environmental chemical hazards New York: J Wiley, 1987: 137-50.

20 Greenland S. Modelling and variable selection in epidemiologic analysis. Am J Public Health 1989;79:340-9.

Accepted 18 February 1991 